Pérez Crespo, José Armando.

Universidad de Guanajuato, México. Profesor asociado del Departamento de Arte y Empresa.

Mukhopadhyay, Tirtha Prasad.

Universidad de Guanajuato, México. Profesor asociado del Departamento de Arte y Empresa.

\title{
Proporciones infradinámicas de Jay Hambidge en las imágenes de la escultura prehispánica Coatlicue
}

\section{Infradynamic proportions of Jay Hambidge in Sculptural Images of the Prehispanic Coatlique}

TIPO DE TRABAJO: comunicación.

PALABRAS CLAVE

Descomposición algorítmica, rectángulo infradinámico, Jay Hambidge, Coatlicue prehispánica.

KEYWORDS:

Algorythmic decomposition, Coatlique, Hambidge, Infradynamic rectangle, prehispanic.

RESUMEN

En el contexto del tema de la conferencia, que es Imagen [n] visible, presentamos una metodología para el análisis de imágenes sobre el tema prehispánico en la escultura de la divinidad Coatlicue, a través de una descomposición algorítmica programada de acuerdo con los principios de efectos visuales definidos por Jay Hambidge, de una manera que se ajusta a las proporciones matemáticas del rectángulo infradinámico o invisible del autor, quien incorpora la serie de Fibonacci. Este algoritmo explica varios aspectos del arte prehispánico, así como las formas omnipresentes en el arte americano. Nuestro objetivo básico es demostrar cómo la programación dinámica explica ahora las formaciones de Hambidge y por lo tanto, puede utilizarse para explicar un corpus extenso de arte que queda fuera de los objetos estéticos comunes en la práctica de las artes visuales contemporáneas. La escultura de la diosa Coatlicue presenta cotas de 350, 130 y 45 centímetros en altura, frontalidad y profundidad respectivamente, fue descubierta en la segunda mitad del siglo XVIII en el antiguo gran recinto ceremonial de la urbe Tenochtitlan ahora el Zócalo de la Ciudad de México; Coatlicue posee sus orígenes en lo femenino por conducto del dios Ometeotl generador del universo y de los principios dualistas, y a partir de Omecihuatl, símbolo de tierra, fertilidad y alumbramiento.

\section{ABSTRACT}

In the context of the theme of the conference, which is Image [n] visible, we present a methodology for the analysis of images of the prehispanic sculpture of the Coatlique divinity. This done with an algorithmic decomposition programmed following the principles of visual effects defined by Jay Hambidge, in a way that conforms to the mathematical proportions of an infradynamic or invisible rectangle, which also incorporates a Fibonacci series. This algorithm explains several aspects of prehispanic art, as well as the omnipresent forms in American art. Our basic objective is to demonstrate how dynamic programming now explains Hambidge's formations and therefore, can be used to explain an extensive corpus of art that is outside the common aesthetic objects in the practice of contemporary visual arts. The sculpture of the goddess Coatlique presents heights of 350, 130 and 45 centimeters in height, frontality and depth respectively. It was discovered in the second half of the 18th century in the former great ceremonial precinct of the city Tenochtitlan, now the central Zocalo of Mexico City. Coatlique has its origins in the feminine god Ometeotl, a generator of the universe and dualistic principles, and comes from the ancestral Omecihuatl, symbol of land, fertility and birth. 


\section{INTRODUCCIÓN}

[...] una mirada que no estuviera armada podría muy bien acercar algunas figuras semejantes y distinguir otras por razón de tal o cual diferencia: de hecho, no existe, ni aun para la más ingenua de las experiencias, ninguna semejanza, ninguna distinción que no sea resultado de una operación precisa y de la aplicación de un criterio previo. Un "sistema de los elementos" —una definición de los segmentos sobre los cuales podrán aparecer las semejanzas y las diferencias, los tipos de variación que podrán afectar tales segmentos, en fin, el umbral por encima del cual habrá diferencia y por debajo del cual habrá similitud- [...] (Foucault, 1996, p. 5)

El presente trabajo inicia con una breve descripción de la cultura azteca en su cronología final, contemplando su sistema de creencias que le relacionan con el origen de la creación y de sus divinidades que permiten la vida bajo la vigilancia de los ciclos de la naturaleza en un concepto bivalente de dualidad; así con el nacimiento de la diosa Coatlicue, madre protectora del ser terrenal ha sido representada en monumental escultura monolítica con atributos iconográficos e iconológicos que han despertado la inquietud de investigadores en diferentes épocas de la historia precolombina. Por otra parte, producto de ello, se ratifica el estado del arte, con el anticipado reconocimiento a expertos que han abordado el tema de la estética del arte mesoamericano con el uso de la composición formal en lo intangiblemente percibido de lo tangible visualizado, mediante recursos de construcciones gráficas y relaciones aritméticas que se basan en la geometría áurea. Además, se el proceder a una revisión teórica en una descomposición algorítmica básica sobre la forma rectangular, identificando y relacionando los tipos de rectángulo estáticos y dinámicos categorizados por el artista Jay Hambidge, y de su aproximación de igual manera al rectángulo configurado en la teoría de Leonardo de Pisa "Fibonacci"; a partir de estos posturas, se ha procedido a registrar una imagen directa sobre la escultura de la Coatlicue sitiada actualmente en la sala mexica del Museo Nacional de Antropología e Historia de la Ciudad de México, para mediante el recurso del software de CAD, realizar comprobaciones estéticas en las configuraciones rectangulares infradinámicas en la dimensión total y seccionada en cuerpos en el sentido vertical del monolito y que refuerzan el mensaje integral de la cosmovisión azteca con los atributos de la divinidad ya conocida en su sociedad.

\section{La sociedad azteca}

La sociedad azteca pertenece al periodo Postclásico Tardío comprendido ente el año 1400 al 1500 d.C. fase mesoamericana caracterizada por un de gran poder económico y religioso en la zona del altiplano central, sobre la denominación azteca, ha señalado Umberger (2007, p. 167) que corresponde a una situación política y a estilos culturales afines de los grupos asentados en la región, mencionado además, que en uno de los aspectos artísticos, la urbe azteca Tenochtitlan fue el centro de producción de esculturas luego del año 1450 . De la última fase cronológica del imperio se tiene:

Cuando los sorprendió la Conquista, los aztecas eran un pueblo rudo que no había alcanzado todavía el refinamiento cultural de los mayas, los toltecas, los totonacas o lo mixtecas; estaban en plena época de florecimiento, pero las viejas culturas indígenas que habían desaparecido son una muestra elocuente de la esterilidad que alcanzaba al fin a esas grandes civilizaciones, por la falta de un ideal constantemente progresivo, que las hiciera concebir la vida como algo diferente a la repetición, invariable y minuciosa, de las ceremonias para honrar a los dioses. (León-Portilla, 2008a, p. 562)

\section{Origen de la divinidad Coatlicue}

Sobre los antecedentes de la divinidad Coatlicue, existe una genealogía y primigeneidad de donde confluye el concepto de dualidad y recae en un lugar conocido como Omeyocan, de acuerdo a lo redactado por Soustelle (1940) se tiene que es un sitio habitado por dioses: "[...] es el lugar del nacimiento. Se le llama también tlacapillachiualoya, el lugar donde se crean los hijos de los hombres." ( León-Portilla, 2018b, p. 551). Así mismo, en la esencia del Omeyocan existe el dios Ometeotl formado de la nada y de acuerdo lo señalado por Cruz (2014) al ser este un dios y ente antagónico, esta condición le definirá el curso de cuanto existe, de la encarnación de la nada, el creador del orden y del caos; con Ometeotl se desprenden las divinidades Ometecutli masculino y Omecihuatl femenino, la pareja creadora o dioses de la creación de la vida; de Omecihuatl surgirá su manifestación en Coatlicue conocida como "la de falda de serpientes" con atributos que recaen en el simbolismo de la tierra, la gestación, el alumbramiento y la muerte; en forma descendente de Coatlicue se tiene al héroe mexica Huitzilopochtli.

De acuerdo con el análisis e interpretación del esteta Justino Fernández de la monumental escultura Cuatlicue, y con los señalamientos vertidos por León-Portilla (2008c) se tiene una aproximación a la comprensión de la cosmovisión azteca, y su relación con la manifestación artística:

Los aztecas vivieron el principio del movimiento en los dioses, en la vida, en el hombre y en todo ser generado por ellos, por eso su cultura y su arte tienen un sentido dinámico, tras de un aparente estatismo. El ser de su mundivisión es dinámico. Mas hay que aprehender el sentido profundo de ese dinamismo, hay que comprender cómo lo sintieron, pensaron e imaginaron, y para eso hay que volver a Coatlicue, para no apartarnos de nuestro punto de partida y de llegada. (p. 571)

\section{Descubrimiento del monolito}


Según Gurría (1978), de acuerdo a la descripción del informante y conquistador español Andrés de Tapia, sobre el contexto urbano de Tenochtitlan y de "el patio de los ídolos" que contenía setenta y ocho templos (p. 26), se detectó la presencia de esculturas semejantes de los dioses, cuya representación es en piedra de grano bruñida o basalto, poseían medidas de casi tres varas de altura, un equivalente a 2.56 metros, con un grosor de un buey y atributos con culebras ceñidas en la cintura; evocando a una posible correspondencia a la representación escultórica de la Coatlicue (p. 30); la escultura fue encontrada el 13 de agosto de 1792 al realizar trabajos de empedrado de la antigua gran plaza.

\section{Estado del Arte}

Se tiene un antecedente que ha inspirado a la presente exploración, relacionado con el estudio de la geometría y sus aspectos armónicos sobre las manifestaciones artísticas del México antiguo, la destacada Dra. en Arquitectura Margarita Martínez del Sobral presenta en su obra Geometría Mesoamericana (2002), las actividades intelectuales de los sabios mesoamericanos a través de principios geométricos que impactan estéticamente al receptor contemporáneo; en su estudio, modula la vista frontal de la escultura de Coatlicue en su base, con ocho unidades y en su altura con trece unidades; el resultado es valor numérico de 1.625 razón de la sección áurea, y que forma parte de la serie de rectángulos dinámicos y estáticos. En Geometría, número, dimensionamiento y relaciones calendárico-astronómicas en el arte y la arquitectura mesoamericanas, contempla su consigna: "Bajo una concepción holística que concibe el macrocosmos y el microcosmos como una unidad, [...] las superficies y volúmenes que circunscriben las obras artísticas obedecen a constantes astronómicas o calendáricas que se expresan por medio de relaciones numéricas recurrentes."

Santos (2001) en Indagaciones estéticas, Espacio mesoamericano refiere a Justino Fernández con un particular talento, sobre la descripción de la Coatlicue: "simetrías, masas, formas, simbolismos y equilibrios quedan cuenta del contenido, tanto estético como de sus significados mítico-religiosos, y pone en relieve el extraordinario avance de la filosofía nahuatlaca, vinculado a lo más preciado de los pueblos: su arte". (p. 19); continuando, Santos realiza un esquema geométrico con el uso de líneas en diagonal sobre los espacios abiertos en conjuntos urbanos con edificaciones piramidales, de estos últimos los perfiles diagonales sobrepasan la formalidad llegando a una interpretación con mayor profundidad filosófica al relacionar lo ascendente y descendente en la dualidad entre la vida y la muerte. (pp. 22-23)

\section{METODOLOGÍA}

\section{Descomposición algorítmica y el rectángulo infradinámico de Jay Hamidge}

Los criterios que permiten realizar un análisis de trazado geométrico sobre la imagen de la escultura de la Coatlicue, se sustenta en la construcción de la simetría dinámica de Jay Hambidge, quien ha categorizado al rectángulo en dos grupos, el primero utilizará números enteros o fraccionarios en su conformación, cuya relación entre sus lados corresponde a ciertas combinaciones tales como 3/2,4/3,4/1, $3 / 1, \ldots$ y denominados rectángulos estáticos; en el segundo grupo, el arreglo geométrico se sustenta a partir del módulo cuadrangular V2 de donde la construcción generadora es una constante con valor de 1, determinados como rectángulos dinámicos, como ha señalado García (2010):

“[...] Un cuadrado (o bien un rectángulo V1); cada vez que aumenta, el módulo que se agrega resulta ser un porcentaje de 1, [...] ilustraré lo anterior con tres ejemplos:

a) Un rectángulo $\sqrt{2}$ (cuya razón es igual a 1.41) está formado por un cuadrado y una 0.414 parte de 1; al sumar las partes da como resultado 1.414 .

b) Un rectángulo $\sqrt{ } 4$ (razón igual a 2) está formado por dos módulos iguales a 1; sumadas las partes da como resultado una razón igual a 2 .

c) Un rectángulo $\sqrt{ } 5$ (razón igual a 2.236) está formado por un cuadrado y 1.236 veces 1 , al sumar las partes da como resultado 2.236." (p. 84)
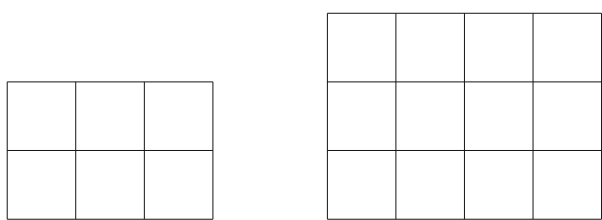

Figura 1. Nótese qué el arreglo geométrico de los rectángulos estáticos mostrados, se definen por ejemplo en razón de 3/2 (izquierda) y $4 / 3$ (derecha), y sus módulos contienen números enteros o fraccionarios. 


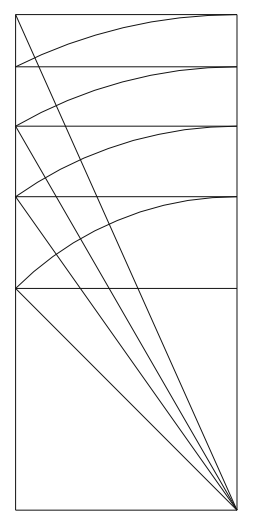

Figura 2. En el arreglo rectangular mostrado, se presenta una modulación dinámica, expresada en una numeración irracional emparentada en el término $\sqrt{5}$, comenzando con el módulo cuadrangular 1, y lo que representaría a un conjunto de reglas determinadas que en pasos y permutas algorítmicas dará la posibilidad de contar con el rectángulo infradinámico de Jay Hambidge.

Con relación a la serie universal de Leonardo de Pisa (1175-1230) Fibonacci "hijo de Bonaccio", su concepto de sucesión progresiva aritmética y geométrica se ha definido como una sucesión recurrente de orden 2, de donde se obtiene un valor nuevo a partir de la suma de los dos valores anteriores, donde los dos primeros términos han sido establecidos sin variación, por ejemplo:

\begin{tabular}{|l|l|l|l|l|l|l|l|l|}
\hline 1 & 1 & 2 & 3 & 5 & 8 & 13 & & 21 \\
\hline $1+1$ & $2+3$ & $5+8$ & & $8+13$ \\
\hline
\end{tabular}

Tabla I. Sucesión progresiva de Fibonacci.

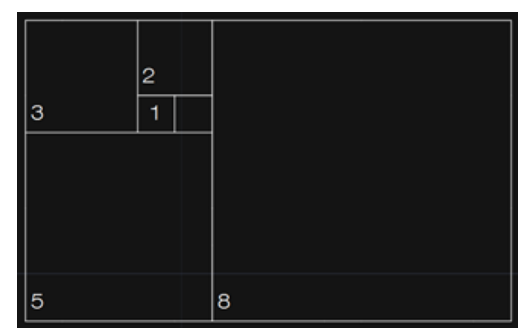

Figura 3. El arreglo numérico de la serie de Fibonacci puede trasladarse a una construcción gráfica del rectángulo de oro; mostrado en la subsecuente imagen 1.

\section{DESARROLLO}

Se ha procedido a registrar en fotografía a la escultura referida y localizada en el Museo Nacional de Antropología e Historia en la ciudad de México en su sala mexica; por lo tanto, se ha trazado sobre la imagen frontal de la escultura, en el programa de Diseño Asistido por Computadora CAD, trabajando en las siguientes comprobaciones rectangulares: 


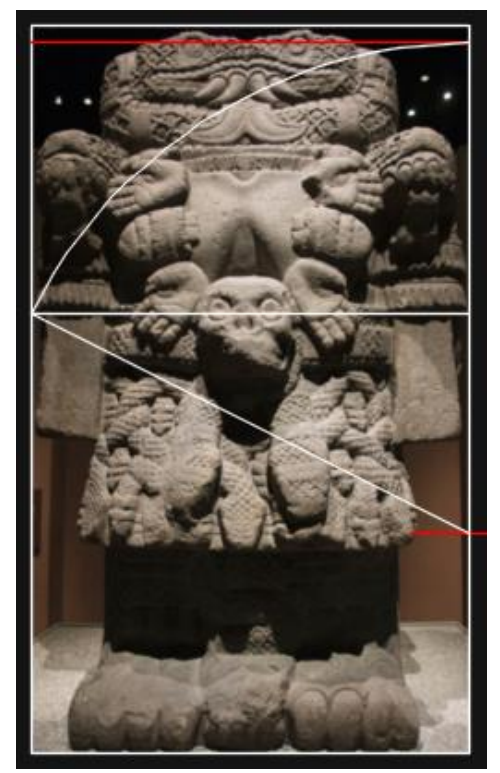

Imagen 1. Se muestra la vista frontal de la escultura, nótese que la base del monolito se ha tomado con el valor de 1 , se comienza con el trazo del rectángulo áureo cuya construcción implicará una extensión de su lado largo en un valor de 0.618 , dando una altura de la escultura en $1+0.618$, que se desprende también de la expresión aritmética: $(1+\sqrt{ } 5) / 2$, esta construcción geométrica se relaciona con el arreglo rectangular conformado por los valores aritméticos de la serie de Fibonacci (Ver Figura 3.) Fotografía de los autores.

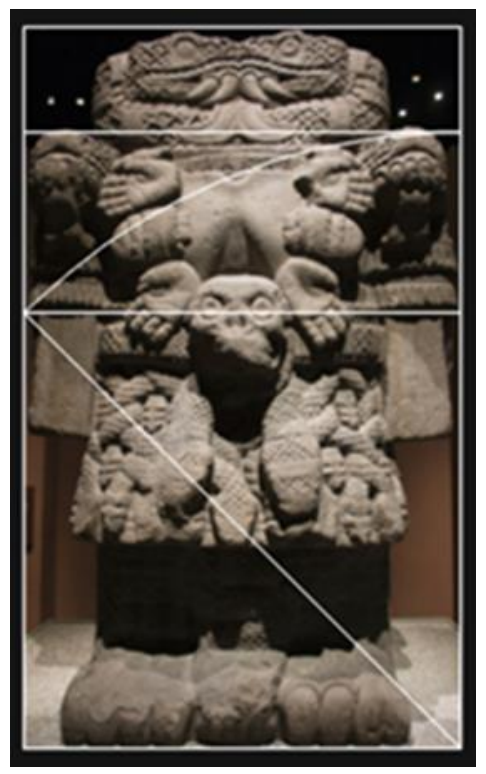

Imagen 2. En el siguiente trazo, se tiene el rectángulo que responde a un número irracional, que permite la construcción gráfica $\sqrt{2}$ con un valor de 1.414 unidades, lo que posiciona una línea a la altura del desplante de la cabeza de la divinidad. Fotografía de los autores. 


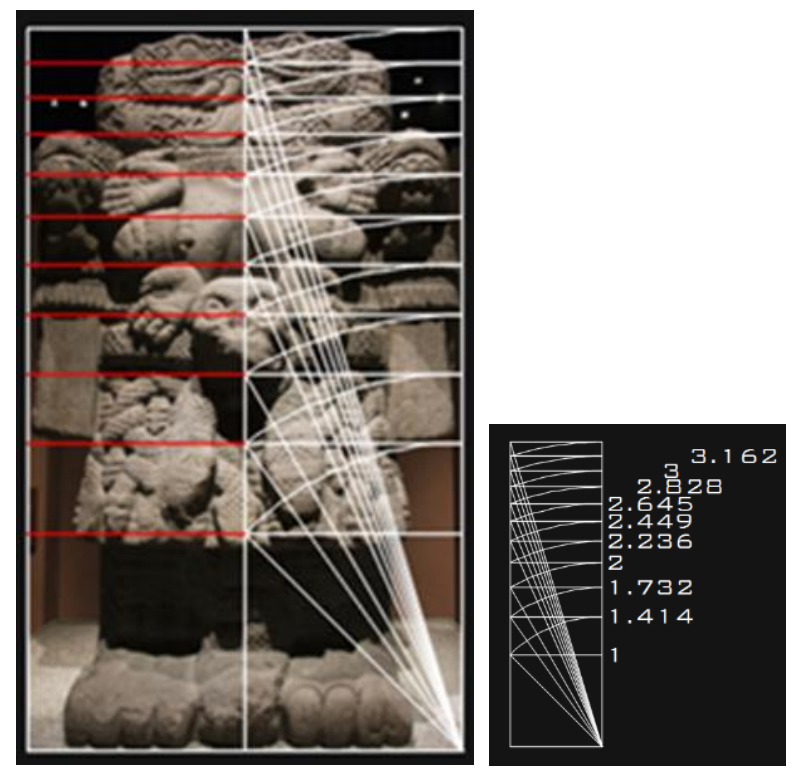

Imagen 3. Habilitando un eje simétrico en el sentido vertical sobre la vista frontal, se origina una reconfiguración de módulo cuadrangular ubicado en la base del monolito; partiendo de ello hacia una construcción algorítmica secuencial desde $\mathrm{V} 1=1, \mathrm{~V} 2=1.144, \mathrm{n} . .$. nótese que los límites de cada nuevo rectángulo dinámico se han extendido simétricamente en líneas rojas horizontales y laterales coincidiendo con ciertos sectores en los relieves y motivos ornamentales de la escultura. Fotografía de los autores.

\section{CONCLUSIONES}

Con el apoyo descriptivo de los atributos contenidos en los relieves de la escultura, Cruz (2014, pp. 9-13) en su Análisis iconográfico e iconológico de la Coatlicue menciona que la representación de la divinidad, en su cabeza posee dos serpientes de perfil confrontadas que otorgarían una percepción en la configuración de un solo rostro, y en una correspondencia al concepto de dualidad; Gendrop (2001) anota al respecto, sobre la raíz Cóatl que en voz náhuatl aparece con el significado de serpiente, siendo la serpiente un motivo artístico muy recurrente en el México antiguo (p. 56); otros motivos de este sector superior es que su conjunto contempla los relieves de las fauces y la presencia de una lengua bífida; por lo tanto, complementando la información producto de la geometría de Jay Hambidge se ha comprobado que los límites inferior y superior de la cabeza corresponden a los rectángulos V8 al V11. Continuando, y de acuerdo con la descripción de la autora, el cuello de "mujer serpiente" contiene un collar de manos y corazones que remata en su centro con un cráneo que cubre parcialmente sus senos flácidos, de donde aparecen los motivos que le declaran jerarquía: el pensamiento (cabeza), el sentimiento (corazón) y las manos (acción), donde la triada se sintetiza en una dualidad que refleja en los conceptos de batalla y la muerte como símbolo glorioso del héroe mexica, este tratamiento ornamental abarca del valor $\mathrm{V} 4$ al $\mathrm{V} 8$; de donde el valor $\mathrm{V} 4=2$ se percibe en una centralización al relieve del cráneo en su eterna vigilancia y en su dominio sobre el ciclo de la vida del hombre. En referencia a la falda de serpientes, que comprende entre los valores del $\sqrt{ } 1$ al $\sqrt{ } 4$, se tiene para este sector relieves con motivos que reflejan la relación con lo terreno y lo humano en cuanto a la sabiduría en un constante movimiento de la vida, decadencia y muerte, y su mensaje metafórico reforzado con el cambio de piel del reptil. Sobre el módulo $\mathbf{V} 1=1 \mathrm{el}$ monolito posee de acuerdo a lo señalado por Cruz, unos adornos de tiras de cuero que se entrelazan, rematados por caracoles. Por lo tanto, y luego de esta revisión comprendida entre la teoría algorítmica de Jay Hambidge y los aspectos fundamentales de la iconografía e iconología de la escultura, se tiene una nueva posibilidad de apreciación estética que relaciona dos conceptos armónicos en apariencia distantes en el tiempo y espacio, para lo que en un momento han postulado culturas clásicas como la de Grecia antigua, y en un aparente contraste con lo creado por una de las culturas amerindias más influyentes como la azteca y que gracias a la exploración de los rectángulos dinámicos se permite una unificación estética. ¿Qué nuevas posibilidades se presentan a partir de ello? Una vez que la estética bidimensional ha sido revisada como en el caso citado, se abre la oportunidad de elaborar proyectos con objetos artísticos en ambientes y configuraciones geométricas tridimensionales, es decir, plantear una estética 3D con el uso nuevos medios y su tecnología, y que permita dar innovadora continuidad y permanencia del patrimonio artístico de la humanidad conectando los diferentes contextos culturales. 


\section{FUENTES REFERENCIALES}

Cruz, P. (2014). Análisis iconográfico e iconológico de la Coatlicue. Horizonte Histórico, 10. México: UAA. Recuperado en https://revistas.uaa.mx/index.php/horizontehistorico/article/view/1266

Foucault, M. (1968). Las palabras y las cosas. Una arqueología de las ciencias humanas. Argentina: Siglo veintiuno editores.

García, E. (2010). Fundamentos geométricos del diseño y la pintura actual. México. Trillas.

García-Cuerva, G. (2014). Medida y proporción en la expresión artística. España: Universidad de la Rioja, Servicio de Publicaciones.

Gendrop, P. (2001). Diccionario de arquitectura mesoamericana. México: Trillas.

Godoy, I. (2006). Coatlicue: visión holográfica. Escritos, Revista del Centro de Ciencias del Lenguaje, 33, 79-92.

Gurría, J. (1978). Andrés de la Tapia y la Coatlicue. Estudios de cultura náhuatl, 13, 23-34. Recuperado en https://dialnet.unirioja.es/servlet/articulo?codigo=3833709

León-Portilla, M. (2018). Antología. De Teotihuacán a los aztecas. Fuentes e interpretaciones históricas. México: UNAM. Instituto de Investigaciones Históricas. Colegio de Ciencias y Humanidades. Recuperado en

http://www.historicas.unam.mx/publicaciones/publicadigital/libros/teotihuacan aztecas/132 0401 Introduccion.pdf

Martínez, M. (2000). Geometría Mesoamericana. México. Fondo de Cultura Económica. Recuperado en https://arquitectura.unam.mx/nuevos-paradigmas-mvp.html

Santos, L. (2001). Indagaciones estéticas. Espacio mesoamericano. Territorios. pp. 18-26. En Repositoriodigital.ipn.mx

Umberger, E. (2007). Historia del arte y el imperio azteca: la evidencia de las esculturas. Revista Española de Antropología Americana, 37(2), 165-202. Recuperado en http://revistas.ucm.es/index.php/REAA/article/view/REAA0707220165A 